\title{
HISTÓRIA, CINEMA E LITERATURA: INTERMIDIALIDADES EM O AMOR DE PEDRO POR JOÃO E O DIA EM QUE DORIVAL ENCAROU A GUARDA
}

\author{
Leticia Sangaletti ${ }^{1}$
}

\begin{abstract}
Resumo: Propomo-nos a investigar como ocorre a relação entre literatura e cinema, apontando, através dos conceitos de intermidialidade, que fatos relacionados à história da ditadura militar aparecem nos objetos analisados. Também pesquisamos o que do texto literário foi utilizado na versão audiovisual, e que elementos foram incluídos no novo produto. Como corpus da na análise, selecionamos o oitavo capítulo do livro $O$ amor de Pedro por João (1982), de Tabajara Ruas, e o curta-metragem baseado em tal excerto, $O$ dia em que Dorival encarou a guarda (1986), com direção de Jorge Furtado. Para tanto, utilizamos como metodologia a Literatura Comparada, de Tânia Carvalhal, e a análise audiovisual, de Manuela Pernafria. O embasamento teórico dessa investigação está calcado nos textos sobre intermidialidade de Claus Cluver e Irina Rajewsky, conta com estudos acerca da teoria da adaptação de Linda Hutcheon, e outros textos de autores que nos permitem discutir as relações entre literatura e cinema.
\end{abstract}

Palavras-chave: História. Literatura. Cinema. Intermidialidade.

Abstract: We propose to investigate how the relationship between literature and cinema occurs, pointing out, through the concepts of intermidiality, that facts related to the history of the military dictatorship appear in the analyzed objects. We also researched what the literary text was used in the audiovisual version, and what elements were included in the new product. As a corpus of the analysis, we selected the eighth chapter of Tabajara Ruas' book O amor de Pedro por João (1982), and the short film based on such excerpt, The Day Dorival Faced the Guard (1986), directed By Jorge Furtado. For that, we used Tânia Carvalhal's Comparative Literature as a methodology and Manuela Pernafria's audiovisual analysis. The theoretical basis of this research is based on the texts on intermidiality of Claus Cluver and Irina Rajewsky, with studies about the theory of adaptation of Linda Hutcheon, and other texts of authors that allow us to discuss the relations between literature and cinema.

Keywords: History. Literature. Movie theater. Intermidialidade.

Doutoranda em Letras pela Universidade Federal do Rio Grande do Sul - UFRGS. E-mail: leticiasangaletti@hotmail.com 


\section{Introdução}

A literatura e o cinema apresentam uma afinidade: a narração de enredos, mesmo com linguagens diferentes, uma textual e outra visual. Desse modo, nos propomos a investigar como ocorre a relação entre literatura e cinema, apontando, através dos conceitos de intermidialidade, que fatos relacionados à história da ditadura militar aparecem nos objetos analisados.

Além disso, também pesquisamos o que do texto literário foi utilizado na versão audiovisual, e que elementos foram incluídos no novo produto, considerando que cada pessoa faz uma leitura diferente das obras, tendo em vista suas vivências e experiências pessoais.

Entendemos que a importância deste estudo se dá em vista de que uma das funções da crítica literária é avaliar o valor dos textos no contexto em que estão inseridos. Nessa conjuntura, este trabalho analisa o diálogo entre literatura e cinema. Para tanto, selecionamos como corpus da na análise, o oitavo capítulo do livro O amor de Pedro por João (1982), de Tabajara Ruas, e o curta-metragem baseado em tal trecho da obra literária, $\mathrm{O}$ dia em que Dorival encarou a guarda (1986), com direção de Jorge Furtado.

\section{Intermidías: Cinema e Literatura}

O termo Intermidialidade abrange, de acordo com Claus Clüver (2006), toda a tradição dos estudos comparados das artes e também as relações com diferentes mídias. Até então, usava-se o termo interartes, que ficou entendido como insuficiente para a gama de produtos envolvidos no comparatismo.

A combinação de "artes e mídias", com a qual já nos deparamos, bem como o termo "intermidialidade", já corrente no âmbito científico alemão, sugere a escolha deste ou de outro nome bem semelhante para uso internacional. Intermidialidade diz respeito não só àquilo que nós designamos ainda amplamente como "artes" (Música, Literatura, Dança, Pintura e demais Artes plásticas, Arquitetura, bem como formas mistas, como Ópera, Teatro e Cinema), mas também às "mídias" e seus textos, já costumeiramente assim designadas na maioria das línguas e culturas ocidentais (CLÜVER, 2006, p. 18). 
A necessidade de buscar um termo que possa ser usado internacionalmente, abrangendo artes, mídias e seus textos, faz com que o termo de Estudos Interartes seja substituído por Intermídias, já que, de acordo com o autor, o termo Intermidialidade já era recorrente no âmbito científico alemão, diz respeito ao que é designado largamente como "artes", ou seja, Música, Literatura, Dança, Pintura e demais Artes plásticas, Arquitetura, bem como formas mistas, como Ópera, Teatro e Cinema, e também às "mídias" e seus textos (CLÜVER, 2008). Assim, o teórico vai definir a Intermidialidade como:

[...] um fenômeno abrangente que inclui todas as relações e todos os tópicos e assuntos tradicionalmente investigados pelos Estudos Interartes. Trata de fenômenos transmidiáticos como narratividade, paródia e o leitor/espectador/auditor implícito e também os aspectos intermidiáticos das intertextualidades inerentes em textos singulares (CLÜVER, 2008, p. 224).

Para Clüver (2011), a teorização dos aspectos de intermidialidade e dos conceitos, termos e métodos usados para estudá-lo, geralmente trata das mídias no sentido coletivo. Por outro lado, aponta o teórico, que a "maioria dos estudos de intermidialidade explora relações e condições de textos individuais e específicos ao invés de aspectos mais generalizados e abstratos das interrelações entre mídias" (CLÜVER, 2011, p. 15). A base teórica utilizada pelo autor para esse tipo de estudo, foi proposta por uma das principais estudiosas do tem. Irina Rajewsky propôs três "subcategorias" de intermidialidade: transposição midiática a combinação de mídias; e as referências intermidiáticas.

Para a estudiosa, a primeira subcategoria trata-se da intermidialidade no sentido mais restrito de transposição midiática, como nas adaptações cinematográficas, onde a qualidade intermidiática está relacionada com a transformação de um determinado produto de mídia (um texto, um filme etc.) ou de seu substrato em outra mídia, no caso, um novo produto (RAJEWSKI, 2012).

A segunda categoria, Combinação de mídias, se refere a fenômenos como ópera, filme, teatro, performance, manuscritos com iluminuras, instalações em computador ou de arte sonora, quadrinhos, entre outras. Nessa subcategoria, a qualidade intermidiática é determinada pelo resultado ou o próprio processo de combinar, no mínimo, duas mídias diferentes, ou o que a estudiosa chama de "duas formas midiáticas de articulação" (RAJEWSKI, 2012, p. 24). 
Já a terceira subcategoria, Referências intermidiáticas, é o que Rajewski (2012) é o que podemos compreender, por exemplo, referências de um filme em um texto literário, através de técnicas cinematográficas como tomadas, edição, fades, montagem. São como estratégias que contribuem para a significação total do produto (RAJEWSKI, 2012, p. 25).

Dentre essas três subcategorias, a primeira é a que se enquadra no processo de intermidialidade que ocorre entre $\mathrm{O}$ amor de Pedro por João e $\mathrm{O}$ Dia em que Dorival encarou a guarda, pois há uma transposição do livro para o filme. $\mathrm{Na}$ próxima seção abordaremos como ocorre a adaptação da literatura para o cinema e como se dá a relação dessas duas artes.

\section{Adaptação e comparatismo: cinema e literatura}

Grande parte das produções cinematográficas do século $X X$ baseou seus roteiros em narrativas consolidadas na literatura. Constituídos em campos de produção de significado diferentes, a literatura e o cinema possibilitam uma relação através da visualidade existente em textos literários, que podem ser transformados em produtos cinematográficos. Ao ser transposto, o texto inicial passa por alteração não só de linguagem, mas também expressa os valores subjetivos, culturais e políticos daquele que o traduz.

Em A Teoria da Adaptação Linda Hutcheon (2011) afirma que nos dias atuais, as adaptações de qualquer tipo estão em todo lugar. Conforme a autora, adaptar não é ser fiel, isso não deve ser considerado na hora de analisar obras adaptadas.

Desse modo, tentando responder algumas perguntas ( $\mathrm{O}$ quê? Quem? Por quê? Como? Onde? e Quando? da adaptação), Hutcheon (2011) propõem três perspectivas diferentes para estudar a prática da adaptação. A primeira é como uma entidade ou um produto formal; Como um processo de criação é a segunda, e a terceira é como um processo de recepção.

A primeira perspectiva, entidade formal ou produto, pode ser compreendida como a adaptação como transposição particular de uma obra, ou seja, uma transcodificação. O que possibilita contar uma história sob outro ponto de vista ou sob nova interpretação. No que concerne a segunda perspectiva, o processo de 
criação, entendemos a adaptação por meio de um processo de reinterpretação e recriação: primeiro se apropria do texto fonte e depois o recria. $\mathrm{Na}$ última perspectiva, o processo de recepção, o texto é baseado em outros textos para ser criado, o que aponta para a adaptação como forma de intertextualidade, há uma relação intertextual (HUTCHEON, 2011).

De acordo com a estudiosa Lucia Sá Rebello (2012) a utilização dos textos literários pelo cinema, acaba gerando eventuais embates entre autores originais e cineastas que procuram fazer a adaptação. Nas palavras da estudiosa, o conflito aparece principalmente pelas diferenças entre literatura e cinema:

O conflito acontece por motivos ímpares e extremamente subjetivos - como é a arte de maneira geral. Mas surge, principalmente, pela natural diferença que há entre os suportes literatura e cinema. $\mathrm{Na}$ transposição de um mundo para o outro, determinados elementos, talvez fundamentais para um autor, podem ser impossíveis de adotar na narrativa audiovisual. É basicamente essa diferença que pressupõe que uma obra cinematográfica seja única e incomparável com o original literário (REBELLO, 2012, p. 11).

Conforme a teórica, certos elementos narrativos que podem ser imprescindíveis para o texto literário, por vezes não conseguem ser adotados pela produção audiovisual. Assim, entendemos que os estudos sobre adaptação traz à tona o fato de que não almeja a narrativa transposta com fidelidade à fonte, mas como outro produto, construído a partir de especificidades, ferramentas e possibilidades próprias. Além disso, Rebello (2012) explica:

Um dos grandes problemas que podem impedir o entendimento claro de que filme e livro são diferentes, talvez esteja na associação direta entre os dois mundos, o que é prejudicial quando a base é uma grande literatura. A relação com o texto original (ou de partida) é sempre conflituosa, pois a sua transposição não pode ser uma tradução literal sendo necessariamente uma "transcriação". A questão que se impõe é: como preservar um mesmo conteúdo em uma diferente forma? (REBELLO, 2012, p. 11).

Acreditamos que, ao propor estabelecer as relações existentes entre o texto literário e o cinematográfico, é imprescindível respeitarmos as características peculiares de cada um. A possibilidade de transformação de uma narrativa ou 
romance para o cinema permite diferentes interpretações, apropriações e redefinições de sentido. O escritor e o cineasta possuem sensibilidades e propósitos diferentes:

\begin{abstract}
Ainda que pautados nas obras literárias, os diretores imprimem, na película, suas crenças, seus objetivos e sua estilística. Assim, eles buscam ou aproximar, ou traduzir, ou equivaler, ou dialogar, ou corresponder, ou adaptar o texto literário ao cinematográfico, observando as possibilidades de imbricamento de um meio com o outro, tendo em vista aquilo que desejam expressar (CURADO, 2007, p. 2-3).
\end{abstract}

A literatura, como o cinema, relaciona-se diretamente às manifestações existenciais do homem; contudo, por meio de sua linguagem própria e caráter visual, exprime não apenas situações pelas quais um indivíduo pode ou não experimentar situações diferentes, mas também a interioridade e o fluxo de consciência de uma pessoa, dependendo da obra (REHN, 2010).

Por outro lado, o romance não possui trilha sonora nem a simultaneidade de leitura, que é proporcionada pelas imagens em vídeo, gerando uma leitura não linear da narração. Assim, entendemos que o espaço narrativo do cinema possui infinitos detalhes visuais, além de constituir um espaço físico literal e figurativo, diferente do que é apresentado no texto literário (CORSEUIL, 2009). Se levarmos em conta as diferenças citadas, observamos que as comparações sobre recriações fílmicas podem ser mais produtivas quando levam a uma reflexão crítica a respeito dos efeitos criados pela adaptação.

Compreendemos que a transposição para o cinema não depende apenas da concepção do responsável pela história, mas também de como ele a transmitirá, envolvendo o desempenho de diversos atores, suas ações na indústria cinematográfica, a ideologia do filme, e ainda os elementos narrativos e a linguagem específica do cinema.

Além disso, esse processo está aliado à importância de avaliar e respeitar o momento histórico-cultural em que ambas as obras foram produzidas e estão inseridas, levando em conta questões próprias da produção cinematográfica. Isso posto, é hora de pensarmos: a que processos Furtado recorre para traduzir o texto literário de Ruas, e que efeitos essa tradução provoca? 


\section{O Dorival de Ruas x Dorival de Furtado: Intermidialidades}

Publicado depois de 18 anos de sua produção, O amor de Pedro por João é um romance que aborda a ditadura militar e foi escrito durante o período de exílio do autor, Tabajara Ruas, que utiliza todo o contexto da época na nova obra literária.

O romance é dividido em 12 capítulos e seis partes, possui uma narrativa fragmentada, é um texto não linear no que tange à sua temporalidade e há, no decorrer do texto, diversas mudanças de foco narrativo dos oito protagonistas que aparecem no enredo. Isso aponta para a extrema fragmentação do texto, o que pode indicar a situação vivida pelas pessoas que combatiam o governo militar. Assunto que rende outra pesquisa.

Os personagens principais da narrativa são Marcelo, Mara, João Guiné, Sepé, Dorival e Ana, e os comunistas mais antigos no movimento Degrazia, que participou da Coluna Prestes, em 1924, e Josias, do Partido Comunista. Como personagens secundários, temos o Micuim, Alemão, Sargento Aparício Grosso, e o torturador denominado "Doutor".

Dorival era um dos rebeldes adultos, considerando que personagens, como Marcelo e Mara, representavam jovens comunistas. Ele é o protagonista da segunda parte do oitavo capítulo, que foi adaptada ao cinema, virando um curta premiado e representativo no que tange ao enfrentamento da ditadura militar.

$\mathrm{Na}$ obra literária esse trecho começa com a personagem Alemão perguntando a Dorival como é a história dele ter enfrentado a guarda, naquele momento, estavam em outubro de 1968, em Porto Alegre. Após relutar um pouco, a personagem acaba contando o fato ocorrido quando ficara preso em Santa Catarina. Dorival queria tomar banho e acaba desafiando e desacatando todas as patentes. Ao final, mesmo sendo espancado, ele consegue o banho que tanto queria.

Em 1986 o curta-metragem de quase 15 minutos de duração é lançado sob direção de Jorge Furtado e José Pedro Goulart. O filme recebeu cerca de oito premiações somente no ano de lançamento, como Melhor Curta, Melhor ator, Prêmio Juri Popular e Prêmio da Crítica no Festival de Gramado; Melhor Filme e Prêmio da Crítica no Festival de Huelva, na Espanha; e Melhor Curta no Festival de 
Havana, em Cuba. Mais tarde, em 1991, é parte da Seleção oficial do Sundance Festival.

Foram poucas as mudanças realizadas na adaptação, algumas, para dar mais sentido a narrativa, de acordo com o que estava sendo narrado. No trecho a seguir retirado roteiro, escrito por Ana Luiza Azevedo, Giba Assis Brasil, Jorge Furtado e José Goulart, podemos observar que há pouca mudança do texto fonte:

\footnotetext{
PRAÇA

Ele diz que vai armar um escândalo, que vai começar a gritar. Aliás, já começou. E é um negrão desse tamanho, parece King Kong.

CABO

Um negrão desse tamanho? Porra, Catarina, tu vem interromper a minha leitura pra me dizer que um negrão desse tamanho, numa cela trancada a chave, começou a gritar, rapaz? (AZEVEDO, et. Al,).
}

Nesse trecho, imagens de um macaco King Kong aparecem na tela, fazendo uma analogia ao tamanho do detendo Dorival, que é um homem negro e de porte grande. Também é possível indicar, nesse excerto, que no livro o cabo está lendo um livro do Drácula, porém no curta, a imagem passa do close no macaco, para uma tomada que se passa em uma história de faroeste, em que uma donzela precisa ser salva.

Há uma sequência de visitas à cela, primeiro o praça, que está de ronda, depois o cabo, seguido pelo sargento e por fim, o tenente. No livro, Dorival fala para o praça e para o cabo que está há 10 dias sem tomar banho, para os demais, ele já parte para os gritos após ouvir as negativas sobre o banho. Já no filme, a reclamação de que está sem tomar banho por 10 dias, ocorre para todos os militares que aparecem na cela. Falando em cela, no livro o número dela é 12, no filme é 6 , ou seja, metade do valor numérico, uma diminuição, talvez?.

Identificamos também, um uso excessivo de palavrões como "bosta" e "merda", que são intensificados quando os militares são ofendidos com as frases "milico e merda para mim é a mesma coisa" e em suas variações de cabo, sargento e tenente, tanto no filme quanto no livro. O uso desses termos pode apontar para os militares como algo podre, o estrume da sociedade, considerando o período de ditadura vivido pelas personagens.

Também foi inserido um trecho que mostra o sargento conversando com uma mulher por telefone. Ela está em um ensaio de escola de samba, o que pode indicar 
que a situação ocorre em meados de fevereiro, antes do carnaval. Essa aparição foi para introduzir um trecho em que Dorival diz que seus gritos serão escutados até na Mangueira. "Lá na Mangueira a coisa 'tá' animada, e eu aqui aguentando esses imbecis" (p. 174).

No começo da adaptação, a maior parte dos diálogos é transpassada ao filme, mas depois há supressão de vários trechos.

É importante ressaltarmos que a presença de uma figura negra atrás das grades recebendo xingamentos como macaco, negro, crioulo, pode indicar o preconceito racial, mas também podemos fazer uma analogia ao fato de uma minoria social estar lutando pelo direito de tomar um banho. Assim como as minorias de nossa sociedade lutam por seus direitos civis e como a população foi às ruas contra a ditadura e por seus direitos, sofrendo as mais diversas e duras punições.

Nessa esteira, lembremos que um dos pontos que marcou o período de Ditadura Militar foi a tortura a civis. Dorival era um militante, e por apenas reivindicar por um banho, foi espancado por inúmeros milicos. É necessário considerar que a personagem utiliza de vários xingamentos para tentar conseguir o que queria. Mas é relevante pensarmos que, após o espancamento do negro da cela 12 , o tenente pede que "limpem o sangue", para isso, Dorival é largado debaixo do chuveiro até que os vestígios da violência fossem escondidos. É a redenção da personagem, que fica em pleno gozo, como se tivesse conseguido o que queria, mesmo que apanhando.

\section{Considerações finais}

A partir da leitura do texto fílmico O Dia em que Dorival encarou a guarda, e o trecho literário de $O$ amor de Pedro por João foi possível os processos que Furtado recorre para traduzir o texto literário de Ruas. Percebemos algumas mudanças no decorrer da narrativa fílmica, como a ordem das ações de personagem e pequenas alterações no enredo, porém concluímos que estas apenas contribuíram para um desfecho mais impactante do produto final.

A direção de Furtado reforça a ideia de que o enfoque maior do filme talvez seja o grito das minorias contra a violência da ditadura militar, considerando o 
contexto em que a narrativa ocorre e a sua função social, sendo um tema tão sério e importante que não pode ser esquecido e, tampouco, discutido.

O cineasta realizou a adaptação de modo a retirar a passagem de uma narrativa maior, que tendo em vista sua fragmentação permitiu que fosse contada separadamente, sem influenciar no restante. Podemos inferir que a adaptação cumpre uma função social e apontam ambas as narrativas, cada uma a partir de seu meio expressivo próprio.

No que tange a relação entre literatura e cinema, percebemos que, de acordo com os conceitos de intermidialidade, a adaptação trata-se de uma transposição literária, tendo em vista que sua narrativa é transposta para outra mídia, o que constroi um novo produto.

O amor de Pedro por João merece uma leitura mais atenta que possa pontar toda a fragmentação da narrativa e os recursos estéticos e formais. Além disso, uma análise dos períodos históricos que aparecem no livro também merecem um estudo atento. Quanto à obra fílmica, há várias estratégias utilizadas que devem ser estudadas, como cortes de cena, uso de excertos de filme, a inserção de música e escola de samba, que, com certeza, possuem um significado importante para a narrativa.

\section{REFERÊNCIAS}

CLÜVER, Claus. Intermidialidade. In: Pós: Revista do Programa de Pós-graduação em Artes. - Vol. 1, n. 2 (novembro 2011). Belo Horizonte: Universidade Federal de Minas Gerais, Escola de Belas Artes, 2011. Disponível em: https://www.eba.ufmg.br/revistapos/index.php/pos/article/view/16/16 Acesso em: $15 / 06 / 2016$

Intermedialidade e Estudos Interartes. In: NITRINI, Sandra; PEREIRA, et all (org). Literatura, artes, saberes. São Paulo, SP: Editora Hucitec, 2008, p.209 - 232.

. Inter textus/ Inter artes/ Inter media. In: Revista Aletria. Belo Horizonte. Programa de Pós-Graduação em Letras - Estudos Literários. v. 6, p. 1-32, jul.- dez,

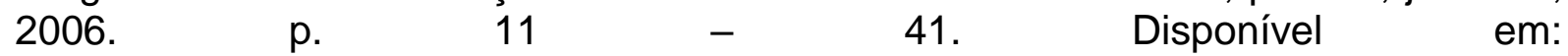
http://www.letras.ufmg.br/poslit/08_publicacoes_txt/ale_14/ale14_cc.pdf. Acesso em: 6 setembro 2016. 
CORSEUIL, A. R. Literatura e Cinema. In: BONNICI, T; ZOLIN, L. O. (Orgs.). Teoria Literária: Abordagens históricas e tendências contemporâneas. Maringá: EDUEM, 2003.

CURADO, Maria Eugênia. Literatura e cinema: adaptação, tradução, diálogo, correspondência ou transformação? Temporis[ação], Goiás, v. 1, n. 24, 2007. Disponível em: http://www.nee.ueg.br/seer/index.php/temporisacao/article/view/18/25 Acesso em:

GUALDA, Linda Catarina. Literatura e cinema: pontos de contato entre Dom Casmurro e Dom. Baleia na Rede. Revista online do Grupo Pesquisa em Cinema e Literatura. Vol. 1, oo 6, Ano VI, Dez/2009 ISSN - 1808 -8473 330. Disponível em: http://www.marilia.unesp.br/Home/RevistasEletronicas/BaleianaRede/Edicao06/1b D om Casmurro e Dom.pdf, Acesso em: 28/08/2012.

RAJEWSKI, Irina O. Intermidialidade, intertextualidade e "remediação": uma perspectiva literária sobre a intermidialidade. In: DINIZ, haïs Flores Nogueira (org.). Intermidialidade e estudos interartes: desaios da arte contemporânea. Belo Horizonte: Ed. UFMG, 2012, p. 15-45.

REBELLO, Lúcia Sá. Literatura Comparada, Tradução e Cinema. In: Organon. v. 27, n. 52, 2012. Edição eletrônica: http://seer.ufrgs.br/organon/article/view/33475

REHN, Andrea de Cássia Jardim. Estudo comparado entre literatura e cinema. Análise comparatista entre Pride and prejudice de Jane Austen e o filme homônimo de Joe Wright. Cadernos do IL. Porto Alegre, n.․ 41, dezembro de 2010. p. 48-61. Disponível em: http://www.seer.ufrgs.br/cadernosdoil/ . Acesso em: 18/07/2012.

STAM, Robert. Do texto ao intertexto. In: Trad. Fernando Mascarello. São Paulo: Papirus, 2003. Introdução à teoria do cinema. 